\title{
Conselho de Administração das Empresas de Governança Corporativa Listadas na BM\&Fbovespa: análise à luz da entropia da informação da atuação independente
}

\author{
Geovanne Dias de Moura ${ }^{1}$ \\ Ilse Maria Beuren ${ }^{2}$
}

\section{Resumo}

A propriedade acionária concentrada de empresas pode resultar em ambiente de conflitos na relação entre acionistas minoritários e majoritários. A governança corporativa busca minimizar esse conflito, tendo o conselho de administração como principal órgão de atuação. Porém, a atuação dependerá do seu nível de independência, que está associado com a maior ou menor influência dos acionistas controladores. O estudo objetiva verificar se o conselho de administração das empresas listadas no Nível 1, Nível 2 e Novo Mercado da BM\&Fbovespa atua de maneira independente em relação aos acionistas controladores sob a ótica da entropia da informação. Pesquisa descritiva, com abordagem quantitativa, foi realizada por meio de pesquisa documental. A população da pesquisa compreende as companhias abertas da BM\&Fbovespa e a amostra compõe-se das 156 participantes dos níveis de governança corporativa. Nas Informações Anuais (IAN) das empresas foram coletados os dados referentes ao exercício findo em 31/12/ 2009. Os dados foram organizados em tabelas, evidenciando-se aspectos do conselho de administração, o total de cada item e suas respectivas médias. Como a análise pela média pode resultar em viés, para testar se o conselho de administração das empresas possui as configurações obtidas pelas médias, foi calculada a entropia da informação. Os resultados indicaram um ambiente com possibilidade de conflitos, pois existe concentração de capital principalmente entre as empresas do novo mercado. Conclui-se que em virtude da forte influência dos controladores no conselho de administração, seus membros não atuam de maneira independente e podem ter suas atuações de redução de conflito de agência prejudicadas.

Palavras-chave: Atuação independente. Conselho de administração. Acionistas controladores. BM\&FBOVESPA.

\footnotetext{
${ }^{1}$ Mestre em Ciências Contábeis pela Universidade Regional de Blumenau -FURB. End.: Rua Antônio da Veiga, 140 - Sala D 202, Victor Konder, Blumenau -SC. CEP: 89012-900 - Brasil. E-mail: geomoura@terra.com.br.

${ }^{2}$ Doutora em Controladoria e Contabilidade pela Faculdade de Economia, Administração e Contabilidade -FEA/USP. Professora do Programa de Pós-Graduação em Ciências Contábeis da Universidade Regional de Blumenau -FURB. End.: Rua Antônio da Veiga, 140 - Sala D202, Victor Konder, Blumenau -SC. CEP: 89012-900 - Brasil. E-mail: ilse@furb.br.

Artigo recebido em: 29/07/2010. Aceito em: 13/12/2010. Membro do Corpo Editorial Científico responsável pelo processo editorial: Martinho Isnard Ribeiro de Almeida.
} 


\section{Introdução}

Com a dispersão do capital das empresas, ocorrida principalmente a partir da Revolução Industrial, a separação entre a propriedade e o gerenciamento do capital tornou-se cada vez mais evidente (ANDRADE; ROSSETI, 2007; ÁLVARES et al. 2008; SANTOS, 2009). A separação de propriedade e gestão é tratada na teoria da agência, que teve como primeiros formalizadores Jensen e Meckling (1976), em um estudo em que descrevem que a teoria da agência examina as relações entre principais e agentes.

Jensen e Meckling (1976) mencionam que o proprietário do capital é designado como principal e o administrador desses recursos como o agente, pois, agenciam os recursos monetários transferidos pelo principal. Nesse contexto, o agente pode tomar decisões que não sejam compatíveis com as diretrizes determinadas pelos interesses do principal.

Famá e Kayo (1997, p. 2) descrevem que

[...] a suposição de que o administrador deva agir sempre em benefício do proprietário é simplista e esconde vieses de comportamento do administrador que podem prejudicar a empresa.

Assim, ocorre um conflito de interesses, que representam os conflitos de agência. Todavia, na maioria dos países, inclusive no Brasil, a propriedade acionária é concentrada, o que gera um ambiente em que os conflitos mais relevantes são observados na relação entre acionistas minoritários e majoritários (VALADARES; LEAL, 2000; DUTRA; SAITO, 2002; SILVEIRA, 2002).

Surge então a necessidade de mecanismos que contribuam para minimização desses conflitos e auxiliem na proteção dos direitos dos acionistas minoritários. Como forma de minimizar esse conflito aparece a Governança Corporativa que, por meio de práticas gerais de conduta, contribui para reduzir o conflito (SHLEIFER; VISHNY, 1997; LA PORTA et al., 2000; SILVEIRA, 2004; PEREIRA; VILASCHI, 2006; ANDRADE; ROSSETTI, 2007; SANTOS, 2009).

A governança apresenta um cenário composto por órgãos de controle e monitoramento das práticas adotadas, sendo que o conselho de administração é um desses órgãos. Oliveira e Costa (2004, p. 2) destacam que ele é "[...] o centro das discussões sobre governança corporativa e também o prin- 
cipal representante dos acionistas e grupos de interesse na companhia". Álvares et al. (2008) mencionam que o conselho de administração é constituído por indivíduos com poderes efetivos mediante a gestão da corporação.

Fama (1980) argumenta que o conselho de administração é o mecanismo de controle interno central para monitorar os gestores. Porém, a atuação do conselho de administração dependerá do seu nível de independência que está associado com maior ou menor influência dos acionistas controladores (VALADARES; LEAL, 2000; DUTRA; SAITO, 2002).

Diante do exposto, justifica-se analisar a configuração do conselho de administração das empresas, para verificar a sua independência em relação aos acionistas controladores que podem influenciar, de maneira prejudicial, a atuação do conselho de administração na redução dos conflitos de agência. Assim, emerge a pergunta de pesquisa que orienta este estudo: o conselho de administração das empresas listadas no Nível 1, Nível 2 e o Novo Mercado da BM\&Fbovespa atua de maneira independente em relação aos acionistas controladores?

Portanto, este estudo objetiva verificar se o conselho de administração das empresas listadas no Nível 1, Nível 2 e o Novo Mercado da BM\&Fbovespa atua de maneira independente em relação aos acionistas controladores sob a ótica da entropia da informação. A motivação para este estudo decorre da crescente visibilidade e interesse que a governança corporativa vem despertando em empresas, governos e países, inclusive no Brasil, nos últimos anos. Estudar a configuração dos conselhos de administração das empresas se torna relevante e desafiador à medida que isso pode contribuir para fortalecer o entendimento sobre o tema.

O estudo está estruturado em sete seções, iniciando com esta introdução. Em seguida, apresenta-se o referencial teórico, que aborda conflitos de agência, governança corporativa e conselho de administração. Após, aborda-se a metodologia utilizada para o desenvolvimento da pesquisa. Em seguida, faz-se a descrição e a análise dos resultados e, por último, apresentam-se as considerações finais do estudo.

\section{Conflitos de Agência}

Segundo Lopes e Martins (2007), a clássica teoria econômica aponta para uma atuação racional das firmas, sempre otimizando lucros, pois, o pro- 
prietário e único interessado pela empresa é também o gestor, portanto, não existem conflitos. Porém, os autores relatam que com o surgimento da corporação moderna, a separação de propriedade e a gestão possibilitaram o surgimento de conflitos de interesse. A separação de propriedade e a gestão resultaram no problema clássico do conflito de agência, que é tratado pela literatura na teoria da Agência.

Os primeiros formalizadores dessa teoria foram Jensen e Meckling (1976), em um estudo em que discutiram que a teoria da agência examina as relações entre principais e agentes, ou seja, entre os interessados diretos em decisões e os indivíduos que realmente têm o poder delegado para decidir. Jensen e Meckling (1976, p. 5) definem a relação de agência como "[...] um contrato pelo qual uma ou mais pessoas (o principal) contratam outra pessoa (o agente) para executar algum serviço em favor deles e que envolve delegar alguma autoridade para a tomada de decisão do agente". Os autores descrevem ainda que, se ambas as partes são maximizadoras de utilidade, pode-se acreditar que o agente não irá atuar sempre conforme os interesses do principal.

Entretanto, La Porta et al. (1999) relatam que na maioria dos países a propriedade concentrada é a estrutura predominante nas empresas de capital aberto, que muda o foco do problema de agência para a relação entre os acionistas controladores e os minoritários. Portanto, o reconhecimento da teoria da agência pela expressão principal-agente não se restringe apenas ao proprietário e administrador. A relação principal-agente é de caráter amplo e alcança a relação entre acionais minoritários e majoritários.

Trata-se do caso do Brasil, onde há forte concentração do capital conforme citado nos estudos de Valadares e Leal (2000), Silveira (2002), Campos (2006), Okimura, Silveira e Rocha (2007). Isso resulta no ambiente de conflitos entre os acionistas controladores e minoritários, de acordo com La Porta et al. (1999). Segundo Okimura, Silveira e Rocha (2007), o poder de controle de um acionista controlador pode possibilitar o uso de recursos da empresa em benefício próprio, enquanto os outros acionistas minoritários arquem de maneira parcial com os custos.

Okimura, Silveira e Rocha (2007) mencionam como exemplos o pagamento de salários excessivos para si próprios, a autonomeação em cargos executivos privilegiados e as posições no conselho para si próprios ou para familiares e parentes. Eles citam ainda o deságio na transferência de ações, o pagamento de preços de transferência elevados para empresas das quais são proprietários, a utilização de ativos da empresa como garantia em emprésti- 
mos pessoais e as decisões de investimentos que reduzem seus riscos ao não maximizar o valor da empresa.

Sendo assim, o agente em determinado momento pode assumir um comportamento oportunista no tocante as suas ações ou omissões, visando maximizar o seu bem-estar ou satisfação pessoal, ocasionando o problema central de análise da teoria da agência (MARTINEZ, 1998; SILVEIRA, 2002).

Segundo Jensen e Meckling (1976), como o agente não atua sempre visando o melhor interesse do principal, torna-se necessário estabelecer incentivos aos agentes e, também, técnicas de monitoramento, cuja finalidade é incentivá-los a buscar a maximização da riqueza do acionista ou protegêlos de ações inadequadas. Os autores relatam ainda que é praticamente impossível garantir que o agente tome sempre as melhores decisões, de acordo com os interesses do principal, a custo zero. Nesse sentido, apontam os custos de monitoramento incorridos pelo principal como sendo um dos custos de agência.

Em relação ao monitoramento, Kimura, Lintz e Suen (1998) descrevem que na tentativa de diminuir os conflitos de interesses, o principal pode realizar auditorias, exigir relatórios internos, realizar visitas periódicas, entre outros, tais mecanismos de controle representam custos ao principal. Outra forma de alinhar os interesses é por meio da Governança Corporativa, que atua por meio de práticas gerais de conduta e, assim, contribui para reduzir o conflito de agência (SHLEIFER; VISHNY, 1997; LA PORTA et al., 2000; SILVEIRA, 2004; PEREIRA; VILASCHI, 2006; ANDRADE; ROSSETTI, 2007; SANTOS, 2009).

\section{Governança Corporativa}

A governança corporativa é um dos principais mecanismos de minimização dos conflitos e custos decorrentes do problema de agência. A prática de boa governança nas organizações é um dos recursos que proporciona maior transparência a todos os agentes envolvidos com a empresa (VIERA; MENDES, 2004).

Shleifer e Vishny (1997, p. 738) realizaram um dos principais estudos sobre governança corporativa sob a ótica da teoria da agência, em que descrevem governança corporativa como sendo um "[...] conjunto de mecanismos pelos quais os fornecedores de recursos garantem que obterão para si o 
retorno sobre seu investimento". Portanto, é uma possibilidade dos investidores se assegurarem de que terão o retorno do que foi aplicado.

O Código das melhores práticas de governança corporativa, do Instituto Brasileiro de Governança Corporativa (IBGC, 2009, p. 19), enuncia como princípios básicos da governança corporativa a transparência, a equidade, a prestação de contas e a responsabilidade corporativa. Descreve governança como "[...] o sistema pelo qual as organizações são dirigidas, monitoradas e incentivadas, envolvendo os relacionamentos entre proprietários, conselho de administração, diretoria e órgãos de controle". Dessa forma, uma empresa que possui esse sistema transmitirá maior segurança ao investidor.

Silva (2006, p. 16) descreve que

[...] governança corporativa é um conjunto de práticas que tem por finalidade otimizar o desempenho de uma companhia, protegendo investidores, empregados e credores, facilitando, assim, o acesso ao capital.

Trata-se de um conjunto de práticas que possibilita às empresas adquirirem maior confiança do mercado.

Andrade e Rossetti (2007, p. 24) relatam que

[...] a governança corporativa trata dos meios utilizados pelas corporações para estabelecer processos que ajustem os interesses em conflito entre os acionistas das empresas e seus dirigentes de alto nível.

Segundo os autores, essas ações, além de deixarem a empresa menos exposta aos riscos externos e de gestão, ainda tornam o negócio mais seguro, o que aumenta a confiança dos investidores.

Na medida em que o mercado de capitais desenvolveu-se, segundo Silveira (2002), o assunto ganhou importância no Brasil e foi fundado o Instituto Brasileiro de Governança Corporativa com o objetivo de propagar o tema no país. Silveira (2002) menciona que uma demonstração da importância do tema ocorreu quando a BM\&Fbovespa criou a classificação dos três níveis correspondentes às práticas diferenciadas de governança corporativa.

De acordo com a BM\&Fbovespa (2010), os níveis de Governança Corporativa são segmentos de listagem destinados à negociação de ações emitidas por empresas que se comprometem, voluntariamente, com a ado- 
ção de práticas de governança corporativa adicionais em relação ao que é exigido pela legislação, ampliando os direitos dos acionistas e melhorando a qualidade das informações. Os níveis de Governança Corporativa são assim definidos pela BM\&Fbovespa (2010, s/p):

Nível 1: práticas diferenciadas de governança corporativa, que contemplam basicamente regras de transparência $e$ dispersão acionária;

Nível 2: além das regras de transparência e dispersão acionária exigidas no Nível 1, contempla também as de equilíbrio de direitos entre acionistas controladores $e$ minoritários.

Novo Mercado: conjunto ainda mais amplo de práticas de governança. A grande diferença do Novo Mercado para os Níveis é a proibição de emissão de ações preferenciais: no Novo Mercado, as empresas devem ter somente ações ordinárias.

Depreende-se da literatura que a governança corporativa engloba diversos conceitos inerentes ao relacionamento entre agentes e principais. Portanto, pode ser considerada uma forma de monitoramento dos conflitos de interesse. Para que a governança corporativa possa realizar suas atribuições de maneira efetiva, torna-se necessária a criação oficial de órgãos internos de caráter normativo (SANTOS, 2009).

\section{Conselho de Administração}

O conselho de administração, segundo Silveira (2002), desempenha papel fundamental na governança corporativa e pode ser considerado um importante mecanismo interno que atua na redução dos conflitos de agência. O autor menciona ainda que o conselho de administração contribui tanto nas relações entre acionistas e gestores quanto na relação entre acionistas controladores e minoritários.

Silveira (2002) descreve que o conselho de administração contribui para a redução dos conflitos de agência, controlando e monitorando a gestão da empresa e analisando decisões relevantes. Sob essa ótica, segundo o autor, é necessário um conselho mais independente e ativo para o cumprimento de suas atribuições. 
A função de monitoramento do conselho seria mais efetiva se ele fosse composto principalmente por membros externos, fator este que o tornaria mais independente. Quanto menor a influência dos acionistas controladores sobre os membros do conselho, menor são as chances do conselho agir somente em benefício deles (JENSEN, 1993).

Nessa mesma direção, o código de melhores práticas de governança corporativa do Instituto Brasileiro de Governança Corporativa (IBGC, 2009) recomenda, entre outros aspectos, que o conselho de administração seja composto apenas por conselheiros externos e independentes. De acordo com o IBGC (2009), conselheiros externos e independentes são aqueles contratados por meio de processo formal e com atuação e qualificação bem definida.

Diversos estudos corroboram com o pressuposto de que, para o conselho desempenhar seu papel de maneira eficiente, deveria ser composto principalmente por membros externos (FAMA, 1980; FAMA; JENSEN, 1983; LIPTON; LORSH 1992; JENSEN, 1993; DUTRA; SAITO, 2002; SILVEIRA, 2002; CORREIA; AMARAL; PASCAL, 2009).

Dutra e Saito (2002) analisaram a composição dos Conselhos de Administração de 142 companhias brasileiras listadas na Bovespa com dados do encerramento do exercício de 1999. A partir de uma adaptação da metodologia desenvolvida por Bhagat e Black (2002), eles realizaram uma classificação dos membros do conselho nas categorias de conselheiro representante do grupo controlador, conselheiro interno que participa do conselho e da diretoria, conselheiro afiliado que pode ser ex-funcionário, por exemplo, e o conselheiro independente que não possui nenhuma ligação com a companhia ou seus controladores. Constataram na época forte influência dos acionistas majoritários no conselho de administração, haja vista que os resultados indicaram a predominância de representantes dos acionistas controladores. Entenderam que essas características podiam estar comprometendo o conselho no desempenho da função de monitoramento, quanto à apropriação de benefícios pelos controladores.

Lipton e Lorsh (1992) e Jensen (1993) relatam que outro aspecto fundamental para eficiência do conselho está relacionado com o número de membros que o compõem. Para esses autores, na medida em que o número de membros aumenta, a sua eficiência diminui. Lipton e Lorsh (1992) propõem em seu estudo limitar a dez o número de membros, com preferência para uma composição entre oito e nove.

Com relação ao número de membros, o código de melhores práticas de governança corporativa do Instituto Brasileiro de Governança Corporativa 
(IBGC, 2009) recomenda que o conselho de administração tenha uma composição mínima de cinco e, no máximo, 11 membros.

Correia e Amaral (2009) advertem que o elevado número de conselheiros pode causar problemas de comunicação e coordenação, o que permite o domínio do agente. Além disso, os conselhos numerosos podem favorecer o surgimento de conflitos internos, em virtude de uma possível dificuldade de muitas pessoas chegarem a um consenso nas decisões.

Além disso, Fama e Jensen (1983), Lipton e Lorsh (1992) e Jensen (1993) destacam que para monitorar as atividades da gerência sem influência também é importante que haja separação do papel de presidente da companhia e presidente do conselho. Sobre a segregação de funções de presidente do conselho e diretor-presidente, o código de melhores práticas de governança corporativa do Instituto Brasileiro de Governança Corporativa (IBGC, 2009) informa que deve ser evitado esse acúmulo de funções, para evitar a concentração de poder, que consequentemente resultará em prejuízo de supervisão adequada.

Depreende-se que para o conselho de administração desempenhar seu papel na governança corporativa e ser considerado um importante mecanismo de diminuição dos conflitos de agência deve: possuir principalmente membros externos, não ser formado por um número elevado de conselheiros e haver separação das funções de diretor geral da companhia e de presidente do conselho. Um conselho de baixa atuação nos conflitos de agência é composto majoritariamente de membros internos, elevado número de conselheiros e presidido pelo executivo responsável pela direção geral da empresa (CORREIA; AMARAL, 2009).

\section{Metodologia}

A pesquisa caracteriza-se como descritiva, com abordagem quantitativa, realizada por meio de pesquisa documental. Para Castro (1977, p. 66)

[...] quando se diz que uma pesquisa é descritiva, se está querendo dizer que se limita a uma descrição pura e simples de cada uma das variáveis, isoladamente, sem que sua associação ou interação com as demais sejam examinadas. 
Gil (1994) descreve que a utilização de técnicas padronizadas de coleta de dados é uma das características mais expressivas da pesquisa descritiva.

Quanto à abordagem do problema, trata-se de uma pesquisa quantitativa. Para Martins e Theóphilo (2007, p. 103), uma pesquisa classifica-se como quantitativa quando pode "[...] organizar, sumarizar, caracterizar e interpretar os dados numéricos coletados". Na pesquisa utilizou-se essa estratégia para a abordagem do problema, conforme consta no tópico da descrição e análise dos resultados.

A população da pesquisa compreende as companhias abertas da Bolsa de Valores, Mercadorias e Futuros de São Paulo - BM\&Fbovespa. A amostra estudada compõe-se das 156 companhias abertas participantes do Nível 1, Nível 2 e Novo Mercado da Bolsa de Valores, Mercadorias e Futuros de São Paulo - BM\&Fbovespa. Essas empresas foram selecionadas para a pesquisa por participarem dos níveis de governança corporativa, portanto, devem ter maior compromisso com a transparência das informações ao público.

Os dados referentes à configuração dos conselhos de administração foram coletados na demonstração de Informações Anuais (IAN) das empresas, referentes ao exercício findo em 31/12/2009, disponíveis no site da $\mathrm{BM} \&$ Fbovespa. Dessas IANs também foram extraídos os dados acerca do percentual de capital dos controladores. Na coleta dos dados focalizaram-se os aspectos descritos na Figura 1.

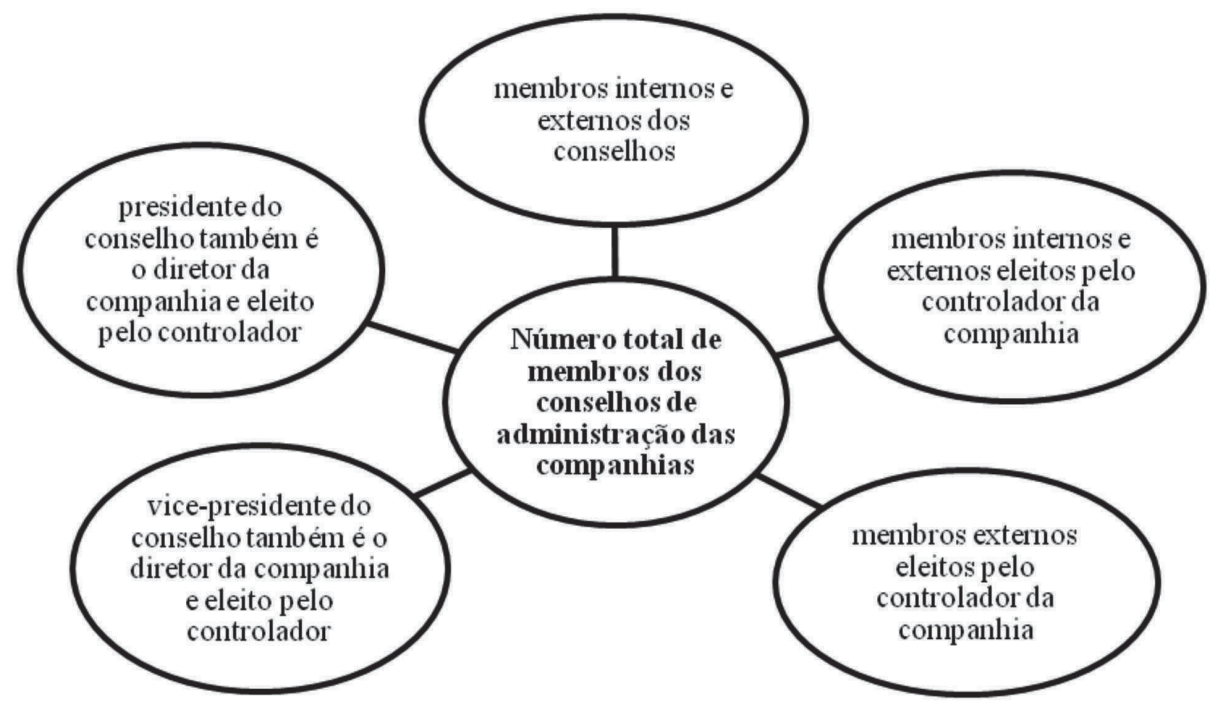

Figura 1: Aspectos pesquisados da configuração dos conselhos de administração das empresas

Fonte: Elaborada pelos autores 
Após a coleta, os dados foram organizados em tabelas em que foi possível identificar o total de cada item e suas respectivas médias. Porém, a análise pela média pode resultar em viés, se poucas empresas possuem números altos, enquanto muitas possuem números baixos, por exemplo. Portanto, para testar se os conselhos de administração realmente possuem o número médio encontrado desses itens, foi calculada a entropia da informação.

Para Zeleny (1982), a entropia da informação pode ser considerada como uma medida simples, mas importante, em razão da quantidade de informações fornecidas com base em uma fonte de informação dada. Segundo o autor, a fórmula do cálculo da entropia segue por meio de alguns passos predefinidos:

Onde $d_{i}=\left(d_{i}^{1}, d_{i}^{2}, \ldots, d_{i}^{m}\right)$ com os valores normalizados, em que: $d_{i}^{k}=\frac{x_{i}^{k}}{x_{i}^{*}}$, identifica o conjunto $\mathrm{D}$, em termos do i-ésimo atributo.

Encontra-se $\mathrm{D}_{\mathrm{i}}=\sum_{\mathrm{k}=1}^{\mathrm{m}} \mathrm{d}_{\mathrm{i}}^{\mathrm{k}} ; \mathrm{i}=1,2, \ldots, \mathrm{n}$. Busca-se a medida de entropia do contraste de intensidade para o i-ésimo atributo por meio de $\mathrm{e}\left(\mathrm{d}_{\mathrm{i}}\right)=-\alpha \sum_{\mathrm{k}=1}^{\mathrm{m}} \frac{\mathrm{d}_{\mathrm{i}}^{\mathrm{k}}}{\mathrm{D}_{\mathrm{i}}} \operatorname{Ln}\left(\frac{\mathrm{d}_{\mathrm{i}}^{\mathrm{k}}}{\mathrm{D}_{\mathrm{i}}}\right)$, onde $\alpha=\frac{1}{\mathrm{e}_{\max }}>0$ e $e_{\max }=\mathrm{Ln}(\mathrm{m})$. Observa-se que $0 \leq \mathrm{d}_{\mathrm{i}}^{\mathrm{k}} \leq 1 e \mathrm{~d}_{\mathrm{i}}^{\mathrm{k}} \geq 0$.

Na fórmula, se todos os $d_{i}^{k}$ forem iguais para um dado $i$, então $\frac{d_{i}^{k}}{D_{i}}=\frac{1}{n}$ e e $\left(\mathrm{d}_{\mathrm{i}}\right)$ terá o valor máximo, ou seja, $e_{\max }=\operatorname{Ln}(\mathrm{m})$. Fixando-se $\alpha=\frac{1}{\mathrm{e}_{\max }}$, determina-se $0 \leq \mathrm{e}\left(\mathrm{d}_{\mathrm{i}}\right) \leq 1$ para todos os $\mathrm{d}_{\mathrm{i}}$ 's. A normalização é necessária para realização do efeito comparativo.

Assim, a entropia total de D é definida pela fórmula: $\mathrm{E}=\sum_{\mathrm{i}=1}^{\mathrm{n}} \mathrm{e}\left(\mathrm{d}_{\mathrm{i}}\right)$.

Desse modo, quanto maior for $e\left(\mathrm{~d}_{\mathrm{i}}\right)$, menor é a informação transmitida pelo i-ésimo atributo. Se e $\left(\mathrm{d}_{\mathrm{i}}\right)=e_{\max }=\mathrm{Ln}(\mathrm{m})$, então, o i-ésimo atributo não transmite informação, podendo ser removido da análise de decisão. Pelo fato do peso $\tilde{\lambda}_{\mathrm{i}}$ ser inversamente relacionado a $e\left(\mathrm{~d}_{\mathrm{i}}\right)$, utiliza-se $1-e\left(\mathrm{~d}_{\mathrm{i}}\right)$ ao invés de $e\left(\mathrm{~d}_{\mathrm{i}}\right)$ e normaliza-se para assegurar que $0 \leq \tilde{\lambda}_{\mathrm{i}} \leq 1$ e $\sum_{\mathrm{i}=1}^{\mathrm{n}} \tilde{\lambda}_{\mathrm{i}}=1$. 
Dessa maneira, a entropia da informação pode ser representada por:

$$
\tilde{\lambda}_{\mathrm{i}}=\frac{1}{\mathrm{n}-\mathrm{E}}\left[1-\mathrm{e}\left(\mathrm{d}_{\mathrm{i}}\right)\right]=\frac{\left[1-\mathrm{e}\left(\mathrm{d}_{\mathrm{i}}\right)\right]}{\mathrm{n}-\mathrm{E}} .
$$

Desse modo, inicialmente identificou-se o número médio de membros: do conselho de administração das companhias; dos membros internos e externos do conselho de administração; dos membros externos eleitos pelo controlador da companhia; do número de empresas em que o presidente do conselho também é o diretor da companhia; do número de empresas em que o vice-presidente do conselho também é o diretor da companhia. Em seguida procedeu-se ao cálculo da entropia da informação, em que foi possível analisar a configuração dos conselhos de administração e identificar se eles atuam de maneira independente em relação aos acionistas controladores.

\section{Descrição e Análise dos Resultados}

Esta seção contém a descrição e análise dos dados coletados. Primeiramente, descreve-se o percentual de capital do controlador das empresas que negociam ações no Nível 1, Nível 2 e Novo Mercado da BM\&Fbovespa. Em seguida, apresenta-se o número de membros dos conselhos e, após, o número de membros internos e externos dos conselhos, número de membros externos eleitos pelo controlador, número total de membros eleitos e não eleitos pelo controlador, número de empresas em que o presidente do conselho de administração é o diretor geral e eleito pelo controlador, e número de empresas em que o vice-presidente do conselho de administração é o diretor geral e eleito pelo controlador.

Na Tabela 1 apresenta-se o percentual de capital do controlador das empresas que negociam ações no Nível 1, Nível 2 e Novo Mercado da BM\&Fbovespa. 
Tabela 1: Percentual de capital do controlador

\begin{tabular}{|c|c|c|c|c|c|c|}
\hline \multirow[t]{2}{*}{$\begin{array}{l}\% \text { de capital do } \\
\text { controlador }\end{array}$} & \multicolumn{2}{|c|}{$\begin{array}{l}\text { Quantidade de empresas } \\
\text { do Nível } 1\end{array}$} & \multicolumn{2}{|c|}{$\begin{array}{l}\text { Quantidade de empresas } \\
\text { do Nível } 2\end{array}$} & \multicolumn{2}{|c|}{$\begin{array}{c}\text { Quantidade de } \\
\text { empresas do Novo } \\
\text { Mercado }\end{array}$} \\
\hline & $\mathbf{N}^{\mathbf{0}}$ & $\%$ & $\mathbf{N}^{\circ}$ & $\%$ & $\mathbf{N}^{0}$ & $\%$ \\
\hline De 0 a 10 & 1 & 3 & - & - & - & - \\
\hline De 11 a 20 & 3 & 9 & 1 & 5 & 2 & 2 \\
\hline De 21 a 30 & 6 & 18 & 3 & 16 & 7 & 7 \\
\hline De 31 a 40 & 8 & 24 & 2 & 11 & 8 & 8 \\
\hline De 41 a 50 & 9 & 26 & 2 & 11 & 8 & 8 \\
\hline De 51 a 60 & 4 & 12 & 3 & 16 & 38 & 37 \\
\hline De 61 a 70 & 3 & 9 & 6 & 32 & 24 & 23 \\
\hline De 71 a 80 & - & - & 1 & 5 & 11 & 11 \\
\hline De 81 a 90 & - & - & 1 & 5 & 1 & 1 \\
\hline De 91 a 100 & - & - & - & - & 4 & 4 \\
\hline Total & 34 & 100 & 19 & 100 & 103 & 100 \\
\hline
\end{tabular}

Fonte: Dados da pesquisa

Inicialmente verificou-se se as empresas de capital aberto que negociam ações no Nível 1, Nível 2 e Novo Mercado da BM\&Fbovespa ainda possuíam como características no ano de 2009 concentração de capital por parte do controlador, conforme citado por Valadares e Leal (2000), Silveira (2002), Okimura, Silveira e Rocha (2004), Campos (2006), que pode resultar em ambiente de conflitos entre os acionistas controladores e minoritários, conforme descrito por La Porta et al. (1999).

Constatou-se, de acordo com a Tabela 1, que entre as empresas do Nível 1, a concentração maior do capital ocorre com os controladores que possuem entre $31 \%$ e $40 \%$ do capital e entre $41 \%$ e $50 \%$ do capital. Em sete empresas, que representam $21 \%$ do total de empresas do Nível 1, o percentual do capital do controlador é superior a $50 \%$.

Entre as empresas do Nível 2, a concentração maior do capital ocorre com os controladores que possuem entre $61 \%$ e $70 \%$ do capital. Em 11 empresas, que representam $58 \%$ do total de empresas do Nível 2 , o percentual do capital do controlador é superior a $50 \%$.

Nas empresas do Novo Mercado, a maior concentração de capital ocorre com os controladores que possuem entre $51 \%$ e $60 \%$ do capital e em 78 empresas, que representam $76 \%$ do total, o percentual do capital do controlador é superior a $50 \%$. 
Nota-se a ocorrência de concentração do capital por parte do controlador, que resulta em ambiente com possibilidades de conflitos de agência conforme descrito na literatura, principalmente nas empresas do Novo Mercado.

Diante de um ambiente com possibilidades de conflitos partiu-se para a etapa seguinte do estudo, que consistiu em verificar se o conselho de administração das empresas da amostra não atua com elevado número de membros conforme sugerem Lipton e Lorsh (1992), Jensen (1993) e o IBGC (2009).

Buscou-se verificar se o conselho é composto principalmente por membros externos e se atua com separação do papel de presidente da companhia e presidente do conselho, cujas características tornariam o conselho mais independente, para melhor atuação nos conflitos de agência, conforme propõem Jensen (1993), Silveira (2002) e o próprio IBGC (2009). Na Tabela 2, evidencia-se o número de membros do conselho de administração dessas empresas.

Tabela 2: Número de membros do conselho de administração

\begin{tabular}{|c|c|c|c|c|c|c|}
\hline \multirow{2}{*}{$\begin{array}{l}N^{0} \text { de membros do } \\
\text { conselho }\end{array}$} & \multicolumn{2}{|c|}{$\begin{array}{c}\text { Quantidade de empresas } \\
\text { do Nível } 1\end{array}$} & \multicolumn{2}{|c|}{$\begin{array}{c}\text { Quantidade de empresas } \\
\text { do Nível } 2\end{array}$} & \multicolumn{2}{|c|}{$\begin{array}{l}\text { Quantidade de empresas } \\
\text { do Novo Mercado }\end{array}$} \\
\hline & $\mathbf{N}^{0}$ & $\%$ & $\mathbf{N}^{\mathbf{o}}$ & $\%$ & $\mathbf{N}^{\circ}$ & $\%$ \\
\hline Abaixo de 5 & 2 & 6 & - & - & 1 & 1 \\
\hline 5 a 6 & 5 & 15 & 5 & 26 & 29 & 28 \\
\hline 7 a 8 & 7 & 21 & 6 & 32 & 36 & 35 \\
\hline 9 a 10 & 11 & 32 & 3 & 16 & 18 & 17 \\
\hline 11 a 12 & 3 & 9 & 4 & 21 & 7 & 7 \\
\hline 13 a 14 & 2 & 6 & 1 & 5 & 2 & 2 \\
\hline 15 a 16 & 3 & 9 & - & - & 3 & 3 \\
\hline 17 a 18 & - & - & - & - & 3 & 3 \\
\hline 19 a 20 & - & - & - & - & 1 & 1 \\
\hline 21 a 22 & - & - & - & - & 3 & 3 \\
\hline 23 a 24 & 1 & 3 & - & - & - & - \\
\hline Total & 34 & 100 & 19 & 100 & 103 & 100 \\
\hline
\end{tabular}

Fonte: Dados da pesquisa

Entre as empresas do Nível 1, a Tabela 2 demonstra que 23 delas ou $68 \%$ possuem um conselho com composição entre cinco e dez membros e apenas sete ou $33 \%$ possuem outras características. Chama atenção o fato de uma empresa do Nível 1 possuir um conselho com composição inferior a cinco membros e outra estar na faixa entre 23 e 24 membros.

Nas empresas do Nível 2, observou-se que 14 delas ou $74 \%$ possuem um conselho com composição entre cinco e dez membros, quatro ou $21 \%$ 
têm composição entre 11 e 12 membros e uma empresa tem o conselho com composição entre 13 e 14 membros.

No Novo Mercado, 83 empresas ou $81 \%$ da amostra possuem um conselho com composição entre cinco e dez membros e 20 ou $19 \%$ possuem outras características.

Com relação ao número de membros do conselho de administração observou-se que a maioria das empresas está em conformidade com Lipton e Lorsh (1992), quando propõem limitar a dez o número de membros e, também, com a recomendação do IBGC (2009) de não ser superior a 11 membros para atuar de maneira mais eficiente.

$\mathrm{Na}$ Tabela 3 apresenta-se o número de membros internos e externos do conselho de administração das empresas por nível de governança.

Tabela 3: Número de membros internos e externos das empresas por nível de governança

\begin{tabular}{|c|c|c|c|c|c|c|c|c|c|}
\hline \multirow[t]{2}{*}{$\begin{array}{l}\text { Nível de } \\
\text { Governança }\end{array}$} & \multicolumn{2}{|c|}{$\begin{array}{c}\mathrm{N}^{0} \text { de membros } \\
\text { internos }\end{array}$} & \multirow{2}{*}{$\begin{array}{l}\text { Entropia } \\
\mathbf{e}\left(\mathbf{d}_{\mathrm{i}}\right)\end{array}$} & \multirow{2}{*}{$\begin{array}{c}\text { Peso da } \\
\text { questão } \\
\lambda_{i}\end{array}$} & \multicolumn{2}{|c|}{$\begin{array}{c}\mathrm{N}^{0} \text { de membros } \\
\text { externos }\end{array}$} & \multirow{2}{*}{$\begin{array}{l}\text { Entropia } \\
\quad e\left(d_{i}\right)\end{array}$} & \multirow{2}{*}{$\begin{array}{c}\text { Peso da } \\
\text { questão } \\
\lambda_{i}\end{array}$} & \multirow[t]{2}{*}{ Total } \\
\hline & $\mathbf{N}^{\circ}$ & $\%$ & & & $\mathbf{N}^{\circ}$ & $\%$ & & & \\
\hline Nível 1 & 34 & 11 & 0,9674 & 0,5125 & 287 & 89 & 0,9690 & 0,4875 & 321 \\
\hline $\begin{array}{l}\text { Nível } 2 \\
\text { Novo }\end{array}$ & 15 & 9 & 0,9690 & 0,6245 & 145 & 91 & 0,9814 & 0,3755 & 160 \\
\hline Mercado & 92 & 10 & 0,9708 & 0,5568 & 801 & 90 & 0,9768 & 0,4432 & 893 \\
\hline
\end{tabular}

Fonte: Dados da pesquisa

$\mathrm{Na}$ Tabela 3 verifica-se o número de membros internos e externos que compõe o conselho de administração de cada nível pesquisado. Dos 321 membros que compõem o conselho de administração das empresas do Nível 1, nota-se que 287 ou $89 \%$ deles são membros externos, que não possuem outros cargos na empresa. Apenas 34 ou 11\% deles são membros internos, isto é, além de atuarem no conselho de administração, também atuam em outros cargos na empresa.

Os dados revelam uma média de oito membros externos e um membro interno por empresa. Porém, a análise pela média pode resultar em viés, já que algumas poucas empresas podem possuir todos os membros internos da amostra, por exemplo. Portanto, calculou-se a entropia de cada nível de governança para testar se realmente os conselhos possuem o resultado da média, no caso do Nível 1 em torno de um membro interno e oito membros externos.

De acordo com Zeleny (1982), quanto maior for o e $\left(\mathrm{d}_{\mathrm{i}}\right)$, menor será a informação transmitida por ele, ou seja, o grau da entropia será maior quan- 
to mais próximo do zero o e $\left(\mathrm{d}_{\mathrm{i}}\right)$ for. Assim, após calcular o peso $\left(\tilde{\lambda}_{\mathrm{i}}\right)$ de cada questão em relação ao total do grupo (grupo composto por membros internos e externos), observa-se que a questão que apresentou maior e(di) é a que retém a menor entropia e vice-versa. Nota-se que no caso do Nível 1, os membros externos apresentaram $e\left(d_{i}\right)=0,9690$ e os membros internos $e\left(d_{i}\right)$ $=0,9674$, portanto, esse nível de governança apresenta baixa entropia, ou seja, uma baixa variação com relação à média. Desse modo, pode-se afirmar que a maioria dos conselhos de administração das empresas do Nível 1 possui em torno de um membro interno e oito membros externos.

No Nível 2, do total de 160 membros que compõem os conselhos das empresas, 145 ou $91 \%$ deles são membros externos, que não possuem outros cargos na empresa, e apenas 15 ou 9\% deles são membros internos, que além de atuarem no conselho de administração, também atuam em outros cargos. No caso do Nível 2, há uma média de sete membros externos e um membro interno por empresa. Calculando-se a entropia encontrou-se e $\left(\mathrm{d}_{\mathrm{i}}\right)$ $=0,9814$ para os membros externos $e\left(d_{i}\right)=0,9690$ para os membros internos, portanto, esse nível de governança também apresenta pouca variação com relação à média.

Entre as empresas do Novo Mercado, dos 893 membros que compõem os conselhos de administração, 801 ou $90 \%$ deles são membros externos, que não possuem outros cargos na empresa, e apenas 92 ou 10\% deles são membros internos, que além de atuarem no conselho de administração, também atuam em outros cargos da empresa. No Novo Mercado há uma média semelhante ao Nível 2, com sete membros externos e um membro interno por empresa, com a entropia também revelando uma baixa informação transmitida com $e\left(\mathrm{~d}_{\mathrm{i}}\right)=0,9768$ para os membros externos $e\left(\mathrm{~d}_{\mathrm{i}}\right)=0,9708$ para os membros internos. Esse nível de governança também apresenta baixa variação com relação à média.

De forma geral, com relação à entropia, constatou-se baixa variação relativa à média, podendo se inferir que a maioria dos conselhos é constituída por um membro interno e sete membros externos, estando de acordo com o proposto por Fama (1980), Fama e Jensen (1983), Lipton e Lorsh (1992) e Jensen (1993).

Na Tabela 4 expõe-se o número de membros externos eleitos pelo controlador, a fim de verificar a possibilidade de haver influência dos acionistas controladores no conselho das empresas, mesmo tendo um conselho formado em sua maioria por membros externos. 
Tabela 4: Número de membros externos eleitos pelo controlador

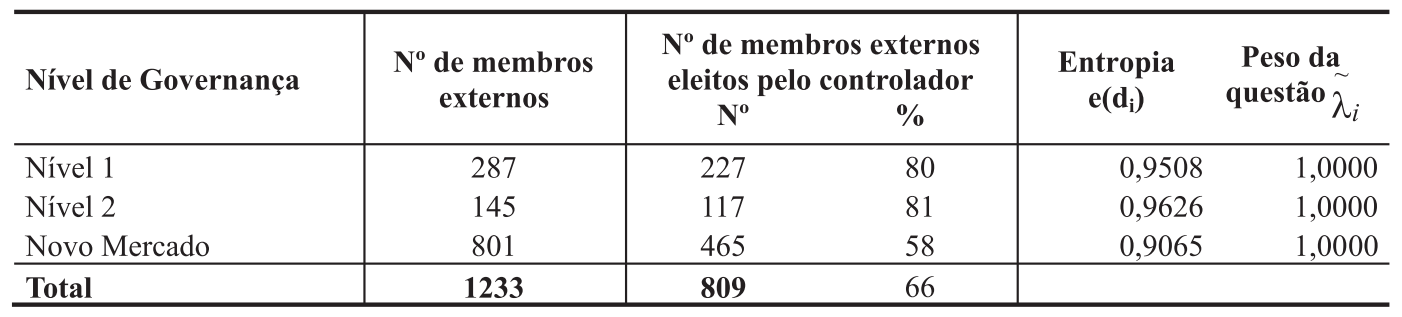

Fonte: Dados da pesquisa

Nota-se na Tabela 4 que das empresas do Nível 1, dos 287 conselheiros externos, 227 deles ou $80 \%$ foram eleitos pelo controlador o que gera a possibilidade de haver alta influência dos acionistas controladores no conselho das empresas do Nível 1, mesmo tendo um conselho formado em sua maioria por membros externos.

Nas empresas do Nível 1, há uma média de sete membros externos eleitos pelo controlador e apenas um membro externo não eleito pelo controlador. Nesse caso, novamente a análise pela média pode resultar em viés, já que algumas poucas empresas também podem possuir todos os membros externos não eleitos pelo controlador, por exemplo. Assim calculou-se a entropia de cada nível de governança para testar se os conselhos de administração possuem quantidades de membros externos eleitos pelo controlador acionista de acordo com a média ou não.

No Nível 1, obteve-se e $\left(\mathrm{d}_{\mathrm{i}}\right)=0,9508$, ou seja, um e $\left(\mathrm{d}_{\mathrm{i}}\right)$ ainda bastante próximo a um, que, segundo Zeleny (1982), significa baixa entropia, neste caso, pouca variação com relação à média, significando que a maioria dos conselhos realmente possuem em torno de sete membros externos eleitos pelo controlador.

No Nível 2, do total de 145 membros externos, 117 ou $81 \%$ deles são membros eleitos pelo controlador. Nesse caso, também, é alta a possibilidade de haver influência dos acionistas controladores no conselho. A média de membros externos eleitos pelo controlador no Nível 2 é de seis membros por empresa. Calculando-se a entropia encontrou-se e $\left(\mathrm{d}_{\mathrm{i}}\right)=0,9626$, portanto, esse nível de governança também apresenta pouca variação na formação dos membros do conselho de administração em relação à média.

Entre as empresas do Novo Mercado, dos 801 membros externos eleitos pelo controlador que compõem os conselhos de administração, 465 ou $58 \%$ deles são eleitos pelo controlador, que resulta em uma média inferior, 
comparado com os outros níveis de governança. A média é equivalente a cinco membros externos eleitos pelo controlador, mas apesar de ser inferior aos demais níveis ainda é alta, o que também leva a crer que exista alta influência dos acionistas controladores no conselho.

A entropia dos membros do Novo Mercado, comparado com os outros níveis, foi o menor, pois apresentou $e\left(\mathrm{~d}_{\mathrm{i}}\right)=0,9065$, um pouco mais distante de um, significando uma variação um pouco maior, relativa à média, porém ainda garantindo que a maioria dos conselhos de administração apresentam-se semelhantes à média.

De maneira geral, neste item de análise também constatou-se baixa variação em relação à média, sendo o Novo Mercado, o nível em que houve maior variação entre a configuração dos conselhos. As empresas do Nível 1 possuem em torno de sete membros externos eleitos pelo controlador; do Nível 2 possuem em torno de seis membros; e do Novo Mercado possuem em torno de cinco membros externos eleitos pelo controlador.

Portanto, na Tabela 3 percebeu-se que a maioria dos membros do conselho de administração das empresas compõe-se de membros externos, mas após análise da Tabela 4 constatou-se que a maioria desses membros externos foram eleitos pelo acionista controlador. Isso resulta em possibilidade de influência do controlador sobre esses membros, comprometendo a independência do conselho, conforme sugerem Fama (1980), Fama e Jensen (1983), Lipton e Lorsh (1992) e Jensen (1993).

Na Tabela 5 demonstra-se o número total de membros do conselho de administração eleitos e não eleitos pelo controlador, no sentido de obter uma visão geral da influência dos acionistas controladores no conselho das empresas.

Tabela 5: Número de membros eleitos e não eleitos pelo controlador

\begin{tabular}{|c|c|c|c|c|c|c|c|c|c|}
\hline $\begin{array}{l}\text { Nível de } \\
\text { Governança }\end{array}$ & $\begin{array}{r}\mathbf{N}^{\circ} \mathbf{d e} \\
\text { ele } \\
\text { con } \\
\mathbf{N}^{o} \\
\end{array}$ & $\begin{array}{l}\text { mbros } \\
\text { pelo } \\
\text { ador } \\
\% \\
\end{array}$ & $\begin{array}{c}\text { Entropia } \\
\mathbf{e}\left(\mathbf{d}_{\mathrm{i}}\right)\end{array}$ & $\begin{array}{c}\text { Peso da } \\
\text { questão } \\
\tilde{\lambda}_{i} \\
\end{array}$ & $\begin{array}{r}\mathrm{N}^{0} \mathrm{de} \\
\text { não e } \\
\text { con } \\
\mathrm{N}^{\circ} \\
\end{array}$ & $\begin{array}{l}\text { mbros } \\
\text { s pelo } \\
\text { ador } \\
\% \\
\end{array}$ & $\begin{array}{c}\text { Entropia } \\
\mathbf{e}\left(\mathbf{d}_{\mathrm{i}}\right)\end{array}$ & $\begin{array}{c}\text { Peso da } \\
\text { questão } \\
\tilde{\lambda}_{i} \\
\end{array}$ & $\begin{array}{l}\text { Total de } \\
\text { membros }\end{array}$ \\
\hline Nível 1 & 259 & 81 & 0,9617 & 0,2585 & 62 & 19 & 0,8900 & 0,7415 & 321 \\
\hline Nível 2 & 130 & 81 & 0,9640 & 0,1156 & 30 & 19 & 0,7245 & 0,8840 & 160 \\
\hline Novo Mercado & 539 & 60 & 0,9202 & 0,3473 & 354 & 40 & 0,8501 & 0,6526 & 893 \\
\hline
\end{tabular}

Fonte: Dados da pesquisa

Na Tabela 5 observa-se que a maioria dos membros dos conselhos de administração das empresas do Nível 1, Nível 2 e Novo Mercado foram elei- 
tos pelo controlador, o que demonstra uma possível dependência de haver alta influência dos acionistas controladores sobre os membros do conselho de administração.

Nas empresas do Nível 1, de um total de 321 membros, 259 ou $81 \%$ deles foram eleitos pelo controlador, o que resulta em uma média de quase oito membros eleitos pelo controlador por conselho de administração. Por meio do cálculo da entropia obteve-se para os membros eleitos pelo controlador $e\left(\mathrm{~d}_{\mathrm{i}}\right)=0,9617$ e para os membros não eleitos pelo controlador $e\left(\mathrm{~d}_{\mathrm{i}}\right)=0,8900$. Esse nível de governança apresenta uma baixa variação em relação à média para os membros eleitos pelo controlador, e uma variação maior entre a quantidade de membros não eleitos pelo controlador nos conselhos de administração.

No Nível 2, do total de 160 membros que compõem os conselhos de administração das empresas, 130 ou $81 \%$ deles foram eleitos pelo controlador, e apenas 30 ou 19\% deles são membros não eleitos pelo controlador. A média de membros eleitos pelo controlador no Nível 2 é de sete membros por conselho e média de um membro não eleito por conselho. Encontrou-se e $\left(\mathrm{d}_{\mathrm{i}}\right)=0,9640$ para membros eleitos pelo controlador e $e\left(\mathrm{~d}_{\mathrm{i}}\right)=0,7245$ para os membros não eleitos pelo controlador. Nesse nível de governança houve pouca variação em relação à média para os membros eleitos pelo controlador e uma variação mais significativa para a quantidade de membros não eleitos pelo controlador.

Entre as empresas do Novo Mercado, dos 893 membros que compõem os conselhos, 539 ou $61 \%$ deles são eleitos pelo controlador, e 354 ou 39\% deles são membros não eleitos pelo controlador. Destaca-se aqui um maior número de membros não eleitos pelo controlador, comparativamente às empresas do Nível 1 e Nível 2. No Novo Mercado há uma média de cinco membros eleitos pelo controlador e três membros não eleitos pelo controlador. A entropia também revelou pouca variação em relação à média para os membros eleitos pelo controlador e uma maior variação para a quantidade de membros não eleitos pelo controlador.

No geral, a entropia demonstrou baixa variação em relação à média dos membros eleitos pelo controlador, que resultou em sete membros para o Nível 1, sete membros para o Nível 2 e cinco membros para os conselhos de administração das empresas do Novo Mercado. Entre os membros não eleitos pelo controlador, a variação foi maior em relação à média, que foi de dois membros para os conselhos das empresas do Nível 1, um membro para 
os conselhos de empresas do Nível 2 e média de três membros para o Novo Mercado. Infere-se que a maioria dos conselhos de administração é constituída por membros eleitos pelo controlador e, portanto, podem prejudicar a sua independência, conforme descrito por Fama (1980), Fama e Jensen (1983), Lipton e Lorsh (1992) e Jensen (1993).

Na Tabela 6 mostra-se o número de empresas em que o presidente é o diretor e foi eleito pelo controlador, com vistas a verificar a segregação de funções que pode interferir na atuação do conselho de administração na redução dos conflitos de agência.

Tabela 6: Número de empresas em que o presidente é o diretor e foi eleito pelo controlador

\begin{tabular}{|c|c|c|c|c|c|}
\hline \multirow{2}{*}{$\begin{array}{l}\text { Nível de } \\
\text { Governança }\end{array}$} & \multicolumn{2}{|c|}{$\begin{array}{l}\mathrm{N}^{0} \text { de empresas em que o } \\
\text { presidente é o diretor da empresa }\end{array}$} & \multicolumn{2}{|c|}{$\begin{array}{c}\mathrm{N}^{\circ} \text { de empresas com presidente } \\
\text { eleito pelo controlador }\end{array}$} & \multirow{2}{*}{$\begin{array}{l}\text { Total de } \\
\text { empresas }\end{array}$} \\
\hline & $\mathbf{N}^{\mathbf{o}}$ & $\%$ & $\mathbf{N}^{\circ}$ & $\%$ & \\
\hline Nível 1 & 3 & 9 & 32 & 94 & 34 \\
\hline Nível 2 & 5 & 26 & 17 & 89 & 19 \\
\hline Novo & & & & & \\
\hline Mercado & 24 & 23 & 83 & 81 & 103 \\
\hline Total & 32 & 21 & 132 & 85 & 156 \\
\hline
\end{tabular}

Fonte: Dados da pesquisa

Fama e Jensen (1983), Lipton e Lorsh (1992), Jensen (1993) e também o IBGC (2009) entendem que, para o conselho de administração poder agir em benefício dos conflitos de agência, não deve ocorrer a segregação das funções de presidente do conselho de administração e o cargo de diretor geral da empresa. Constata-se na Tabela 6 que no Nível 1 em apenas três empresas ocorre a segregação de funções. Porém, a influência do controlador pode estar ocorrendo, pois, das 34 empresas, em 32 delas o presidente do conselho foi eleito pelo controlador.

No Nível 2 ocorre a segregação em cinco empresas, mas o presidente foi eleito pelo controlador em 17 das 19 empresas. E no Novo Mercado ocorre a segregação de funções em 24 , o que equivale a $23 \%$ do total, sendo ainda proporcionalmente inferior ao Nível 2, e em 83 das 103 empresas, o presidente foi eleito pelo controlador. Portanto, na maioria das empresas não ocorre a segregação de funções, porém a influência do controlador pode ocorrer pelo fato de ter eleito o presidente do conselho.

Na Tabela 7 evidencia-se o número de empresas em que o vice-presidente é o diretor e foi eleito pelo controlador, para verificar a segregação 
dessas duas funções e a influência do controlador, que são características que podem interferir na atuação do conselho de administração para a redução dos conflitos de agência.

Tabela 7: Número de empresas em que o vice-presidente é o diretor e foi eleito pelo controlador

\begin{tabular}{|c|c|c|c|c|c|}
\hline \multirow{2}{*}{$\begin{array}{l}\text { Nível de } \\
\text { Governança }\end{array}$} & \multicolumn{2}{|c|}{$\begin{array}{c}\mathbf{N}^{0} \text { de empresas em que o vice- } \\
\text { presidente é o diretor da empresa }\end{array}$} & \multicolumn{2}{|c|}{$\begin{array}{c}\mathrm{N}^{\circ} \text { de empresas com vice- } \\
\text { presidente eleito pelo controlador }\end{array}$} & \multirow{2}{*}{$\begin{array}{l}\text { Total de } \\
\text { empresas }\end{array}$} \\
\hline & $\mathbf{N}^{\circ}$ & $\%$ & $\mathbf{N}^{o}$ & $\%$ & \\
\hline Nível 1 & 6 & 18 & 31 & 91 & 34 \\
\hline Nível 2 & 2 & 11 & 17 & 89 & 19 \\
\hline Novo Mercado & 11 & 11 & 86 & 83 & 103 \\
\hline Total & 19 & 12 & 134 & 86 & 156 \\
\hline
\end{tabular}

Fonte: Dados da pesquisa

Percebe-se na Tabela 7, que no Nível 1 em apenas seis empresas ocorre a segregação das funções de vice-presidente do conselho de administração e a função de diretor geral da empresa. Porém, a influência do controlador também pode estar ocorrendo, pois, das 34 empresas, em 31 delas, ou seja, em $91 \%$ dos casos o vice-presidente do conselho foi eleito pelo controlador.

No Nível 2 ocorre a segregação em apenas duas empresas, mas o vicepresidente foi eleito pelo controlador em 17 das 19 empresas, o que representa $89 \%$. E, no Novo Mercado, ocorre a segregação de funções em 11, e em 86 das 103 empresas o presidente foi eleito pelo controlador. Relativamente ao vice-presidente do conselho de administração, na maioria das empresas não ocorre a segregação de funções, porém, a influência do controlador também pode existir pelo fato de ter eleito o vice-presidente do conselho na maioria dos casos.

\section{Considerações Finais}

O estudo objetivou verificar se o conselho de administração das empresas listadas no Nível 1, Nível 2 e Novo Mercado da BM\&Fbovespa atua de maneira independente em relação aos acionistas controladores sob a ótica da entropia da informação. Esta pesquisa descritiva foi realizada com abordagem quantitativa, por meio de análise documental. A amostra estudada constituiu-se das 156 companhias abertas participantes do Nível 1, Nível 2 e Novo Mercado da BM\&Fbovespa. Os dados foram coletados nas Informa- 
ções Anuais (IAN) das empresas referentes ao exercício findo em 31/12/2009, disponíveis no site da BM\&Fbovespa.

Primeiramente foi verificado se as empresas possuíam como características, no ano de 2009, forte concentração de capital por parte do controlador, conforme citado por Leal e Valadares (2000), Silveira (2002), Okimura, Silveira e Rocha (2004), Campos (2006), que favorece o surgimento de ambientes de conflitos entre os acionistas controladores e minoritários descrito por La Porta et al. (1998). Constatou-se entre as empresas do Nível 1 que a maior concentração do capital ocorre com os controladores que possuem entre $31 \%$ e $50 \%$ do capital; entre as empresas do Nível 2 a concentração maior ocorre com os controladores que possuem entre $61 \%$ e $70 \%$; e nas empresas do Novo Mercado a maior concentração de capital ocorre com os controladores que possuem entre $51 \%$ e $60 \%$ do capital. A concentração constatada de capital por parte do controlador pode originar ambientes de conflitos de agência, conforme descrito na literatura, principalmente nas empresas do Novo Mercado.

Identificado um ambiente com possibilidades de conflito, partiu-se para a etapa seguinte, que foi verificar se os conselhos de administração das empresas da amostra não atuavam com elevado número de membros, conforme sugerem Lipton e Lorsh (1992), Jensen (1993) e o órgão brasileiro que regulamenta as práticas de governança corporativa (IBGC, 2009). Notou-se que a maioria das empresas está de acordo com Lipton e Lorsh (1992), que propõem limitar a dez o número de membros, e com a recomendação do IBGC (2009) de não ser superior a 11 membros para atuar de maneira mais eficiente.

Em seguida buscou-se averiguar as principais características dos conselhos de administração para verificar a sua independente em relação aos acionistas controladores. Iniciando pela quantidade de membros internos e externos de cada nível de governança, foi possível perceber por meio do cálculo da entropia da informação que, de forma geral, os conselhos são constituídos por um membro interno e sete membros externos, estando de acordo com Fama (1980), Fama e Jensen (1983), Lipton e Lorsh (1992) e Jensen (1993).

Verificou-se também que aproximadamente $90 \%$ dos membros do conselho de administração das empresas pesquisadas são externos. Porém, notou-se que $80 \%$ do total de membros externos dos conselhos do Nível 1 foram eleitos pelo controlador; $90 \%$ do total de membros externos dos conselhos do Nível 2 foram eleitos pelo controlador; e quase $60 \%$ do total de membros externos dos conselhos das empresas do Novo Mercado foram elei- 
tos pelo controlador. Isso pode promover elevada influência dos acionistas controladores no conselho de administração dessas empresas.

Como a análise pela média pode resultar em viés, para testar se o conselho de administração de 2009 das empresas realmente possui as configurações obtidas pelas médias encontradas na primeira fase da análise, foi calculada a entropia da informação para conferir maior segurança à análise. O cálculo da entropia revelou baixa variação relativamente à média, sendo que no Novo Mercado houve maior variação entre a configuração dos conselhos. As empresas do Nível 1 possuem em torno de sete membros externos eleitos pelo controlador, o Nível 2 em torno de seis membros e no Novo Mercado em torno de cinco membros externos eleitos pelo controlador.

Analisando o total de membros eleitos pelo controlador, observa-se que aproximadamente $70 \%$ dos membros dos conselhos de administração das empresas do Nível 1, Nível 2 e Novo Mercado foram eleitos pelo controlador. Com o cálculo da entropia encontrou-se baixa variação relativamente à média dos membros eleitos pelo controlador, que resultou em sete membros para o Nível 1; sete membros para o Nível 2; e cinco membros para o conselho de administração das empresas do Novo Mercado. Portanto, a maioria desses conselhos é constituída por membros eleitos pelo controlador e, portanto, podem prejudicar a sua independência, conforme descrito por Fama (1980), Fama e Jensen (1983), Lipton e Lorsh (1992) e Jensen (1993).

Constatou-se também um baixo número de empresas com segregação das funções de presidente do conselho de administração e o cargo de diretor geral da empresa. Porém, a influência do controlador pode ocorrer se considerar-se que, em $85 \%$ das empresas, o presidente do conselho foi eleito pelo controlador. Situação semelhante ocorre no cargo de vice-presidente do conselho, em que também existe um baixo número de empresas com a segregação das funções de vice-presidente do conselho de administração e o cargo de diretor geral, mas em $86 \%$ deles eleito pelo controlador.

Resumindo as características do conselho de administração das empresas analisadas, observa-se que é constituído em sua maioria por membros externos, mas $66 \%$ deles foram eleitos pelo controlador. Do total geral de membros (internos e externos), aproximadamente $70 \%$ deles foram eleitos pelo controlador. O presidente do conselho foi eleito pelo controlador em aproximadamente $65 \%$ dos casos e o vice-presidente do conselho foi eleito pelo controlador em $86 \%$ dos casos. Conclui-se que em virtude da forte influência que os controladores possuem no conselho de administração 
das empresas pesquisadas, os membros não atuam de maneira independente e podem ter suas atuações de redução de conflito de agência prejudicada.

Os resultados da pesquisa provocaram inquietações e que se sugere sejam temas de investigação para futuras pesquisas. Assim, recomenda-se acompanhar a configuração dos conselhos de administração dessas empresas, buscando identificar os impactos de alterações no sistema de governança corporativa das empresas, inclusive estudos comparativos entre setores ao invés de níveis de governança. Também seria interessante comparar os resultados desta pesquisa com os de empresas que negociam suas ações em Bolsas de Valores Americanas.

\section{Board of Directors of Companies Corporate Governance Listed at BM\&Fbovespa: analysis in the light of independent practice entropy information}

\section{Abstract}

The concentrated share ownership of companies can result in environmental conflict in the relationship between minority and majority shareholders. Corporate governance seeks to minimize this conflict, having the board of directors as the main agent. However, the performance will depend on its level of independence, which is associated with more or less influence of controlling shareholders. This study aims to verify whether the board of directors of companies listed on Level 1, Level 2 and the new market of BM\&F Bovespa is independent in relation to controlling shareholders from the viewpoint of entropy information. A descriptive research, with quantitative approach, was conducted through desk research. The survey includes public companies of BM\&F Bovespa and the sample consists of 156 participants in the levels of corporate governance. From the Annual Information (IAN) of companies were collected data for the year ending on 31/12/2009. The data were organized into tables, highlighting aspects of the board of directors, the total of each item and their respective averages. As the analysis by averaging can result in bias, to test if the board of directors of the companies has the settings obtained by the average, the entropy information was calculated. The results indicate an environment with possibility of conflicts, once there is a concentration of capital, mainly among companies in the new market. It is concluded that given the strong influence of the controllers on the board of directors, its members do not act independently and can have their performances to reduce agency conflict affected. 
Key words: Independent acting. Board of directors. Controlling shareholders. BM\&F Bovespa.

\section{Referências}

ÁLVARES, E. et al. Governança corporativa: um modelo brasileiro. Rio de Janeiro: Elsevier, 2008.

ANDRADE, A.; ROSSETTI, J. P. Governança corporativa: fundamentos, desenvolvimento e tendências 3. ed. São Paulo: Atlas, 2007.

BHAGAT, S.; BLACK, B. Board independence and long-term firm performance. The Journal of Corporation Law, v. 27, n. 1, p. 231-273, 2002.

CASTRO, C. M. A prática da pesquisa. São Paulo: McGraw-Hill do Brasil, 1977.

CAMPOS, T. L. C. Estrutura de propriedade desempenho econômico: uma avaliação empírica para as empresas de capital aberto no Brasil. RAUSP, v. 41, n. 4 , p. 369- 380, out./dez. 2006.

CORREIA, L. F.; AMARAL, H. F. A eficiência do conselho de administração como mecanismo de controle dos custos de agência. In: CONGRESSO BRASILEIRO DE CUSTOS, 16, 2009, Fortaleza. Anais... São Leopoldo: ABC, 2009.

CORREIA, L.F.; AMARAL, H.F.; PASCAL, L. Controle dos custos de agência de empresas negociadas na bovespa: os determinantes da eficiência dos conselhos de administração. In: CONGRESSO BRASILEIRO DE CUSTOS, 16, 2009, Fortaleza. Anais... São Leopoldo: ABC, 2009.

DUTRA, M. G. L.; SAITO, R. Conselhos de administração: análise de sua composição em um conjunto de companhias abertas brasileiras. Revista de Administração Contemporânea. São Paulo, v. 6, n. 2, p. 9-27, 2002.

FAMA, E. Agency problems and the theory of the firm. Journal of Political Economy, v. 88, n. 2, p. 288-307, 1980.

FAMA, E. F.; JENSEN, M. C. Separation of Ownership and Control. Journal of Law and Economics, v. 26, n. 2, p. 301-325, june, 1983. 
FAMÁ, R.; KAYO, E. K. Teoria de agência e crescimento: evidências empíricas dos efeitos positivos e negativos do endividamento. Caderno de Pesquisas em Administração, FEA/USP, São Paulo, v. 2, n. 5. $2^{\circ}$ Sem./1997.

GIL, A. C. Métodos e técnicas de pesquisa social. 4. ed. São Paulo: Atlas, 1994.

IBGC - Instituto Brasileiro de Governança Corporativa. Código das melhores práticas de governança corporativa. 4. ed. São Paulo: IBGC, 2009.

JENSEN, M. C.; MECKLING, W. H. Theory of the firm: managerial behavior, agency costs and ownership structure. Journal of Financial Economics, October, 1976.

JENSEN, M. The modern industrial revolution, exit, and the failure of internal control systems. The Journal of Finance, v. 48, n. 3, p. 831-880, 1993.

KIMURA, H.; LINTZ, A. C.; SUEN, A. S. Uma contribuição da teoria de opções para a avaliação dos custos máximos de agência. Caderno de Pesquisas em Administração, FEA/USP, São Paulo, v. 1, n. 6, 1 trim. 1998.

LA PORTA, R. et al. Corporate ownership around the world. Journal of Finance, v. 54, n. 2, p. 471-517, 1999.

LA PORTA, R. et al. Investor protection and corporate governance. Journal of Financial Economics, v. 58, p. 3-27, 2000.

LIPTON, M.; LORSCH, J. A modest proposal for improved corporate governance. Business Lawyer, v. 48, n. 1, p. 59-77, 1992.

LOPES, A. B.; MARTINS, E. Teoria da contabilidade: uma nova abordagem. 2. ed. São Paulo: Atlas, 2007.

MARTINEZ, A. L. Agency theory na pesquisa contábil. In: ENANPAD, 22., 1998, Foz do Iguaçu. Anais... Rio de Janeiro: ANPAD, 1998. CD-ROM.

MARTINS, G. M.; THEÓPHILO, C. R. Metodologia da investigação científica para ciências sociais aplicadas. São Paulo: Atlas, 2007.

OKIMURA, R. T.; SILVEIRA, A. M.; ROCHA, K. C. Estrutura de propriedade e desempenho corporativo no Brasil. Revista de Administração

Contemporânea. São Paulo, v. 1, n. 1, p. 119-135, 2007. 
OLIVEIRA, M. C.; COSTA, P. P. O comitê de auditoria nas companhias abertas brasileiras: um estudo multicaso. Fortaleza, UNIFOR, 2004.

PEREIRA, A. N.; VILASCHI, A. Governança corporativa e contabilidade: explorando noções e conexões. In: SIMPÓSIO FUCAPE DE PRODUÇÃO CIENTÍFICA, 4., 2006, Vitória. Anais... Vitória: FUCAPE, 2006.

SANTOS, A. G. Comitê de auditoria: uma análise baseada na divulgação das informações de empresas brasileiras. Dissertação (Mestrado em Controladoria e Contabilidade) - Programa de Pós-Graduação em Ciências Contábeis da Universidade de São Paulo, São Paulo, 2009.

SHLEIFER, A.; VISHNY, R. A survey of corporate governance. The Journal of Finance, v. 52, n. 2, p. 737-783, jun. 1997.

SILVA, E. C. Governança corporativa nas empresas: guia prático de orientação para acionistas e conselho de administração. São Paulo: Atlas, 2006.

SILVEIRA, A. D. M. Governança corporativa, desempenho e valor da empresa no Brasil. 2002. Dissertação (Mestrado em Administração) Programa de Pós-Graduação em Administração da Universidade de São Paulo, São Paulo, 2002.

\section{SILVEIRA, A. D. M. Governança corporativa e estrutura de}

propriedade: determinantes e relação com o desempenho das empresas no Brasil. Tese (Doutorado em Administração) - Programa de Pós-Graduação em Administração, da Universidade de São Paulo, São Paulo, 2004.

VALADARES, S. M.; LEAL, R. P. C. Ownership and control structure of Brazilian companies. Revista Abante, v. 3, n. 1, p. 29-56, abr. 2000.

VIEIRA, S. P.; MENDES, A. G. S. T. Governança corporativa: uma análise de sua evolução e impactos no mercado de capitais brasileiro. Revista BNDES. São Paulo, v. 11, n. 22, p.103-122, dez. 2004.

ZELENY, M. Multiple criteria decision making. New York: McGraw-Hill, 1982. 